\title{
Correlations between Interleukin-33 and -1 $\alpha$ Levels in Gingival Crevicular Fluid and Plasma in Patients with Chronic or Aggressive Periodontitis and Disease-free Subjects
}

\author{
Sujatha Pai $B^{1)}$ and AR Pradeep ${ }^{2,3)}$ \\ ${ }^{1)}$ Department of Periodontology, DSCDS, Bengaluru, Karnataka, India \\ 2) Department of Periodontology, Government Dental College and Research Institute, \\ Bengaluru, Karnataka, India \\ ${ }^{3)}$ Department of Periodontology, The Oxford Dental College, Bengaluru, Karnataka, \\ India
}

Received 7 January, 2019/Accepted for Publication 19 February, 2019

Published Online in J-STAGE 22 November, 2019

\begin{abstract}
Interleukin (IL)-33 is a dual-function protein that may play important roles as both a cytokine and intracellular nuclear factor. It may also function similarly to prototypical alarmin IL- $1 \alpha$, as an endogenous danger signal to alert innate immune system cells to tissue damage during trauma or infection, as it can be released in the extracellular space after endothelial cell damage or mechanical injury. The aim of this study was to determine possible correlations between concentrations of IL-33 and IL- $1 \alpha$ in gingival crevicular fluid (GCF) and plasma obtained from healthy patients, those with chronic periodontitis (CP), and those with generalized aggressive periodontitis (GAP) patients. Forty-five patients with an age range of 20-60 years were enrolled and divided into 3 groups: Group H, 30 samples (15 GCF and 15 plasma) from 15 patients with healthy periodontium; Group CP, 30 samples from 15 patients with CP; and Group GAP, 30 samples from 15 patients with GAP. The clinical periodontal parameters investigated in all groups comprised the gingival index score, probing pocket depth, and clinical attachment level. The GCF and plasma levels of IL-33 and IL-1 $\alpha$ were quantitated using enzyme linked immunosorbent assay. The mean IL-33 concentrations in GCF and plasma were highest in Group GAP, followed by Group CP, with the lowest in Group H; the difference among them was statistically significant $(\mathrm{p}<0.05)$. Concentration of IL- $1 \alpha$ followed the same trend as that of IL-33 in GCF, but was lower than detection levels in plasma. The GCF and plasma concentrations of IL-33 correlated with IL-1 $\alpha$ concentrations in GCF. Concentrations of IL-33 and IL- $1 \alpha$ in GCF varied significantly between healthy patients and those with disease, allowing healthy patients to be distinguished from those with GAP or CP. The results of this study suggest that IL-33 offers a potential inflammatory marker of periodontal disease, similar to IL- $1 \alpha$.
\end{abstract}

Key words: Cytokine - Chronic periodontitis — Gingival crevicular fluid Aggressive periodontitis - Alarmin 


\section{Introduction}

Periodontal disease results from the inflammatory response to periodontopathic bacteria, where disease progression is due to a combination of high levels of proinflammatory cytokines and low levels of anti-inflammatory cytokines ${ }^{28)}$.

The immune response to infection is regulated by the balance between $\mathrm{T}$ helper (Th) 1- and Th2-type cytokines. The net effect of the former is to enhance cell mediated responses; while that of the latter is to suppress cell mediated responses and enhance humoral immunity. It has been suggested that stable periodontal lesions are mediated by Th1 cells, and progressive lesions by Th2 cells, although this remains controversial ${ }^{29)}$.

The classical Interleukin (IL)-1 family of cytokines especially has been known to play a key role in these disease processes, and hence have been identified as therapeutic targets, too. Excessive or dysregulated activity of these agents is associated with tissue destruction, which is a hallmark of periodontitis ${ }^{6,26)}$.

Interleukin-33 (IL-1F11; previously known as NF-HEV) is the most recent addition to the IL-1 family. It has been shown to induce Th2 responses by signaling through the IL-1 receptor-related protein ST2 (IL-1R4), an orphan member of the IL-1 receptor family, as well as activate NF- $\kappa \mathrm{B}$ and MAP kinases ${ }^{27)}$. In addition, it is also involved in the regulation of innate immune response, particularly via mast cell activation ${ }^{1)}$.

Interleukin-33 is associated with endothelial cells in inflamed tissues in patients with rheumatoid arthritis and Crohn's disease, where it is a nuclear factor which regulates transcription $^{7}$. It is a dual-function protein that may play important roles as both a cytokine and an intracellular nuclear factor ${ }^{7,24)}$. It may function similarly to the prototypical alarmin IL- $1 \alpha$ as an endogenous danger signal to alert cells of the innate immune system to tissue damage during trauma or infection, as it can be released in the extracellular space after endothelial cell damage or mechanical injury ${ }^{18)}$.
The facts that increased microvasculature is a prominent histological finding in periodontitis and that IL-33 plays a role in promoting Th2 responses, (such as those in destructive periodontitis), warrant a detailed investigation of the role of IL-33 in periodontitis ${ }^{26)}$. To date, little is known about the role of IL-33 in periodontal disease since the results of previous studies are varied and inconclusive. Therefore, the aim of the present study was to investigate the presence of IL-33 in gingival crevicular fluid (GCF) and plasma obtained from patients with periodontal disease and determine any correlation with IL- $1 \alpha$, an established alarmin, and clinical parameters of periodontal inflammation.

\section{Materials and Methods}

\section{Study population and clinical examination}

All patients enrolled in this study attended the Outpatient Department of Periodontics at the Government Dental College and Research Institute in Bangalore between February and August 2017. All were selected at random from among individuals scheduled for routine oral examination. Written informed consent was obtained from each participant. Ethical clearance was obtained from the institution's ethical committee and review board (Reference No.: GDCRI/ACM/PG/Ph.D/1/ 2016-2017) and was conducted according to the guidelines of the Helsinki Declaration.

A total of 45 patients (28 men and 17 women; age, 20 to 60 years; mean age, 29.73 years) were divided into the following 3 groups: Group $\mathrm{H}$, comprising healthy patients; Group CP, comprising those with chronic periodontitis; and Group GAP, comprising those with generalized aggressive periodontitis.

Each patient underwent full-mouth periodontal probing and charting, along with radiographic examination. For periodontal evaluation the Gingival Index ${ }^{14)}$ (GI) score, probing pocket depth (PPD), and Clinical attachment level (CAL) were determined. All clinical measurements were performed by a 
single examiner (SPB). Probing pocket depth and CAL were measured using a graduated William'speriodontalprobe(Hu-Friedy, Chicago, IL).

The CP patients showed signs of clinical inflammation, $\mathrm{GI}>1, \mathrm{PPD} \geq 4 \mathrm{~mm}, \mathrm{CAL} \geq 2 \mathrm{~mm}$, and moderate-to-severe alveolar bone loss at multiple sites in all 4 quadrants of the oral cavity, which was commensurate with the amount of plaque accumulation. The GAP patients showed signs of clinical inflammation, GI $>1$, $\mathrm{PPD} \geq 4 \mathrm{~mm}, \mathrm{CAL} \geq 2 \mathrm{~mm}$, and radiographic evidence of bone loss affecting at least 3 permanent teeth other than first molars and incisors. The patients in the CP and GAP groups were selected based on primary features and clinical presentation in accordance with the definition of Lang et $a l^{13)}$. Patients with a clinically healthy periodontium, GI $=0$ (absence of clinical inflammation), $\mathrm{PPD} \leq 3 \mathrm{~mm}$, $\mathrm{CAL}=0$, no evidence of bone loss on radiographs, and no bleeding on probing were included in Group H. The exclusion criteria were as follows: any chronic inflammatory disease such as rheumatoid arthritis; any autoimmune disease or other systemic disease that could alter the course of periodontal disease; a history of smoking or use of tobacco in any form; inflammatory bowel disease such as ulcerative colitis or Crohn's disease; a history of periodontal therapy in the preceding 6 months; pregnant/lactating women; patients with immunodeficiency such as those infected with the Human Immunodeficiency virus; use of medication like steroids, contraceptives, anti-inflammatory drugs, or antibiotics (in the last 6 months); and an unwillingness to participate in the study.

\section{Site selection and GCF collection}

In the periodontitis groups, only 1 site per patient was selected as a sampling site; whereas in the healthy group, multiple sites (3 to 5 sites per patient) with an absence of clinical inflammation were sampled to ensure the collection of an adequate volume of GCF. In patients with chronic or aggressive periodontitis, sites showing the greatest CAL and signs of inflammation along with radiographic evi- dence of bone loss were selected for sampling.

On the subsequent day, the sample collection site was air-dried and well-isolated using sterile cotton rolls, and supragingival plaque was removed gently without touching the marginal gingiva, using a Universal Gracey curette \#4R/4L (Hu-Friedy, Chicago, IL) to avoid contamination of the paper strips. The paper strips (Periopaper, Ora Flow Inc., Amityville, NY, USA) were carefully placed at the entrance of the gingival sulcus/crevice until light resistance was felt, care being taken to avoid mechanical injury, and left in place for 60 seconds. The volume of absorbed GCF in each strip was determined by electronic impedance using a Periotron 8000 (ProFlow Inc., Amityville, NY, USA). Samples suspected of being contaminated with blood or saliva were discarded. After collection of gingival fluid, the 2 periopaper strips per collection site that absorbed GCF from each patient were pooled and immediately transferred to microcentrifuge tubes (premarked with the biomarker name for identification) containing $400 \mu \mathrm{l}$ phosphate buffer saline and stored frozen at $-70^{\circ} \mathrm{C}$ for subsequent analysis.

\section{Blood collection and plasma extraction}

On the same day as GCF collection, $2 \mathrm{ml}$ blood was collected from the antecubital fossa by venipuncture using a $2-\mathrm{ml}$ syringe with a 20-gauge needle and transferred immediately to EDTA containing vials. The plasma was separated from blood by centrifuging at $1,270 \mathrm{~g}$ for $5 \mathrm{~min}$. The plasma was immediately transferred to a plastic vial and stored at $-70^{\circ} \mathrm{C}$ until the time of assay.

\section{ELISA}

The GCF sample tubes were first allowed to reach room temperature, following which they were homogenized for $30 \mathrm{sec}$ and centrifuged for $5 \mathrm{~min}$ at $1,500 \mathrm{~g}$ to elute. The elution was then used as sample for ELISA estimation of IL-33 and IL- $1 \alpha$.

1) IL-33 assay

Interleukin-33 levels in GCF were measured using the Human IL-33 DuoSet ELISA kit 
(R\&D Systems, USA, Imported by BiotechIndia, India) in accordance with the manufacturer's instructions. Absorbance in each well was read on an ELISA reader using $450 \mathrm{~nm}$ as the primary wavelength. Concentrations of IL-33 in the GCF samples were estimated using the standard curve.

2) IL-1 $\alpha$ assay

Interleukin- $1 \alpha$ levels in GCF obtained were measured using the Human IL-1 $\alpha$ Quantikine ELISA kit (R\&D Systems, USA, Imported by Biotech-India, India) in accordance with the manufacturer's instructions. Absorbance in each well was read on an ELISA reader using $450 \mathrm{~nm}$ as the primary wavelength. Concentrations of IL- $1 \alpha$ in the GCF samples were estimated using the standard curve.

\section{Statistical analyses}

Power analysis was used to estimate sample size with a software program $\left(\mathrm{G}^{*}\right.$ power v.3.0.8 for Windows, Heinrich Heine University, Düsseldorf). The SPSS statistical software (SPSS version 18.5, Chicago, IL, USA) was utilized for all statistical analyses. The results were averaged (mean \pm standard deviation) for continuous data. Normality assumptions were tested using the Shapiro-Wilks and Kolmogorov-Smirnov tests. The Kruskal Wallis and Mann-Whitney tests were used as nonparametric tests. Proportions were compared using the Chi square test. Spearman's rho correlation coefficients were calculated to determine whether there were any correlations among the clinical parameters and GCF or plasma concentrations of IL-33 and IL- $1 \alpha$. A $\mathrm{p}$-value of $<0.05$ was considered as statistically significant. Mean intra-examiner standard deviation of differences in repeated PPD and CAL measurements was obtained using single passes of measurements (correlation coefficients between duplicate measurements; $r=0.95)$.

\section{Results}

\section{Clinical findings}

Descriptive statistics of the study popula- tion are shown in Table 1. All values were rounded off to the nearest whole number. Groups GAP and CP showed significantly higher PPD scores than group $\mathrm{H}(\mathrm{p}<0.001)$. The CAL scores were similar between groups CP and GAP $(p=0.126)$. Patients with periodontitis showed significantly higher GI scores $(p=0.003)$. No significant difference was observed in sex distribution between the groups $(p=0.094)$. Mean age in the CP group was significantly higher than that in the GAP or healthy groups $(p<0.001)$, whereas there was no statistically significant difference between the GAP and healthy group.

\section{Biochemical findings}

\section{1) Analysis of IL-33 in GCF and plasma}

Interleukin-33 was detected in all samples. Mean concentrations of IL-33 in GCF according to ELISA readings were $414.36 \pm 49.461$ $\mathrm{pg} / \mathrm{ml}$ in group $\mathrm{H} ; 466.93 \pm 56.206 \mathrm{pg} / \mathrm{ml}$ in group CP; and $543.20 \pm 95.819 \mathrm{pg} / \mathrm{ml}$ in group GAP. The mean IL-33 concentration in GCF was highest in group GAP. The mean GCF IL-33 concentration showed a significant increase, from the healthy to CP groups, and then from the CP to GAP groups $(414.36 \mathrm{pg} / \mathrm{ml}<466.93 \mathrm{pg} / \mathrm{ml}<543.20 \mathrm{pg} /$ $\mathrm{ml})$. Mean concentrations of IL-33 in plasma according to ELISA readings were $13.40 \pm$ $4.304 \mathrm{pg} / \mathrm{ml}$ in group $\mathrm{H} ; 17.67 \pm 8.371 \mathrm{pg} / \mathrm{ml}$ in group CP; and $216.04 \pm 148.436 \mathrm{pg} / \mathrm{ml}$ in group GAP. The mean IL-33 concentration in plasma was highest in group GAP. The mean plasma IL-33 concentration showed a significant increase, from the healthy to CP groups, and then from the $\mathrm{CP}$ to GAP groups $(13.40 \mathrm{pg} / \mathrm{ml}<17.67 \mathrm{pg} / \mathrm{ml}<216.04 \mathrm{pg} / \mathrm{ml})$. To test the hypothesis of equality of means among the 3 groups, the Kruskal-Wallis test was carried out, the results of which indicated that the means differed significantly $(p<0.001)$ among groups in GCF and plasma concentrations of IL-33. Further multiple comparisons using the Mann Whitney $U$ test were carried out to find which pair or pairs differed significantly. The results showed that the differences were statistically significant between all 3 groups for IL-33 in GCF 
Table 1 Descriptive statistics of study population and gingival crevicular fluid and plasma IL-33 and IL- $1 \alpha$ concentrations

\begin{tabular}{|c|c|c|c|c|c|}
\hline PARAMETERS & $\begin{array}{l}\text { GROUP H } \\
\quad(\mathrm{n}=15)\end{array}$ & $\begin{array}{l}\text { GROUP CP } \\
\quad(\mathrm{n}=15)\end{array}$ & $\begin{array}{l}\text { GROUP GAP } \\
\quad(\mathrm{n}=15)\end{array}$ & $\begin{array}{l}\text { F value/ } \\
\text { Chi-square } \\
\text { value }\end{array}$ & p-value \\
\hline AGE (YEARS) & $24.53 \pm 4.658$ & $37.20 \pm 6.428$ & $27.47 \pm 7.945$ & 15.685 & $<0.001^{*}$ \\
\hline \multicolumn{6}{|l|}{ SEX } \\
\hline Women (n) & 9 & 4 & 4 & \multirow{2}{*}{4.727} & \multirow{2}{*}{0.094} \\
\hline Men (n) & 6 & 11 & 11 & & \\
\hline GI & - & $1.90 \pm 0.186$ & $2.36 \pm 0.287$ & 26.540 & $0.003^{*}$ \\
\hline PPD (mm) & $1.87 \pm 0.640$ & $6.07 \pm 1.387$ & $6.93 \pm 1.163$ & 89.661 & $<0.001^{*}$ \\
\hline CAL $(\mathrm{mm})$ & - & $6.93 \pm 1.624$ & $7.80 \pm 1.373$ & 2.491 & $0.126^{*}$ \\
\hline $\begin{array}{l}\text { GCF IL-33 concentration } \\
(\mathrm{pg} / \mathrm{ml})\end{array}$ & $414.36 \pm 49.461$ & $466.93 \pm 56.206$ & $543.2 \pm 95.819$ & 22.031 & $<0.001^{*}$ \\
\hline $\begin{array}{l}\text { Plasma IL-33 concentration } \\
(\mathrm{pg} / \mathrm{ml})\end{array}$ & $13.40 \pm 4.304$ & $17.67 \pm 8.371$ & $216.04 \pm 148.436$ & 30.143 & $<0.001^{*}$ \\
\hline $\begin{array}{l}\text { GCF IL-1 } \alpha \text { concentration } \\
(\mathrm{pg} / \mathrm{ml})\end{array}$ & $174.975 \pm 101.593$ & $309.464 \pm 82.882$ & $623.77 \pm 251.686$ & 33.269 & $<0.001^{*}$ \\
\hline $\begin{array}{l}\text { Plasma IL-1 } \alpha \text { concentration } \\
(\mathrm{pg} / \mathrm{ml})\end{array}$ & $0.15(\mathrm{n}=1)$ & $0.60(\mathrm{n}=2)$ & $<0.15^{* *}$ & - & - \\
\hline
\end{tabular}

* Statistically significant at $\mathrm{p}<0.05 ; \mathrm{F}$ value-Kruskal Wallis test

** below detection limit;

- not applicable

All values except sex expressed as Mean \pm SD

$(\mathrm{p}=0.004, \mathrm{p}<0.001, \mathrm{p}=0.004$, respectively $)$ and were statistically significant between groups $\mathrm{H}$ and GAP $(\mathrm{p}<0.001)$ and groups $\mathrm{CP}$ and GAP $(\mathrm{p}<0.001)$ for plasma IL-33 (Table 2).

2) Analysis of IL- $1 \alpha$ in GCF and plasma

Interleukin- $1 \alpha$ was detected in all GCF samples. Mean concentrations according to ELISA readings were $174.97 \pm 101.593 \mathrm{pg} / \mathrm{ml}$ in group $\mathrm{H} ; 309.96 \pm 82.882 \mathrm{pg} / \mathrm{ml}$ in group $\mathrm{CP}$; and $623.77 \pm 251.686 \mathrm{pg} / \mathrm{ml}$ in group GAP. The mean IL- $1 \alpha$ concentration in GCF was highest in group GAP. The mean GCF IL-1 $\alpha$ concentration showed a significant increase, from the healthy to the CP groups, and then from the CP to the GAP groups $(174.97 \mathrm{pg} / \mathrm{ml}<309.96 \mathrm{pg} / \mathrm{ml}<623.77 \mathrm{pg} /$ $\mathrm{ml})$. To test the hypothesis of equality of means among the 3 groups, the Kruskal-Wallis test was carried out, the results of which indicated that the means differed significantly $(p<0.001)$ among groups in GCF concentrations of IL- $1 \alpha$. Further multiple comparisons using the Mann Whitney $U$ test were carried out to find which pair or pairs differed significantly. The results showed that the differences were statistically significant between all 3 groups for IL- $1 \alpha 1 \alpha$ ( $\mathrm{p}=0.001$, $\mathrm{p}<0.001, \mathrm{p}<0.001$, respectively) (Table 2 ). Interleukin- $1 \alpha$ was detected in only 3 of the 45 plasma samples. In the remaining 42 samples, it was below detection levels. In one of the samples in the $\mathrm{H}$ group, $0.15 \mathrm{pg} / \mathrm{ml}$ was detected; and in the CP group, 2 of the samples had a mean concentration of $0.60 \mathrm{pg} / \mathrm{ml}$. It was not detected in any of the GAP group plasma samples. The remaining samples had $<0.15 \mathrm{pg} / \mathrm{ml}$ of IL- $1 \alpha$, so they were labelled as undetectable. The plasma concentration of IL- $1 \alpha$ was therefore not submitted for statistical analysis.

3) Correlations among IL-33, IL-1 $\alpha$, and clinical parameters

The Spearman's rho correlation test was carried out to determine any possible correlations among IL-33, IL- $1 \alpha$, and clinical param- 
Table 2 Intergroup comparison of gingival crevicular fluid and plasma IL-33 and IL- $1 \alpha$ concentrations using Mann-Whitney Test.

\begin{tabular}{|c|c|c|c|c|c|c|c|c|c|}
\hline \multirow[b]{2}{*}{ Study groups } & \multicolumn{3}{|c|}{ GCF IL-33 } & \multicolumn{3}{|c|}{ GCF IL- $1 \alpha$} & \multicolumn{3}{|c|}{ Plasma IL-33 } \\
\hline & $\begin{array}{c}\mathrm{H} \text { vs } \\
\mathrm{CP}\end{array}$ & $\begin{array}{l}\text { H vs } \\
\text { GAP }\end{array}$ & $\begin{array}{l}\text { CP vs } \\
\text { GAP }\end{array}$ & $\begin{array}{c}\mathrm{H} \text { vs } \\
\mathrm{CP}\end{array}$ & $\begin{array}{l}\text { H vs } \\
\text { GAP }\end{array}$ & $\begin{array}{l}\text { CP vs } \\
\text { GAP }\end{array}$ & $\begin{array}{c}\mathrm{H} \text { vs } \\
\mathrm{CP}\end{array}$ & $\begin{array}{l}\mathrm{H} \text { vs } \\
\text { GAP }\end{array}$ & $\begin{array}{l}\text { CP vs } \\
\text { GAP }\end{array}$ \\
\hline $\begin{array}{l}\text { Mann-Whitney } \\
U \text { value }\end{array}$ & 44.500 & 12.000 & 44.000 & 34.500 & 0.000 & 4.000 & 80.500 & 0.000 & 0.000 \\
\hline 'p' value & $0.004^{*}$ & $<0.001^{*}$ & $<0.004^{*}$ & $0.001^{*}$ & $<0.001^{*}$ & $<0.001^{*}$ & $0.187^{*}$ & $<0.001^{*}$ & $<0.001^{*}$ \\
\hline
\end{tabular}

* statistically significant at $\mathrm{p}<0.05$

eters. Correlations among GCF or plasma concentrations of IL-33 and IL- $1 \alpha$ and clinical parameters were statistically insignificant in all 3 groups. There was a weak-to-moderate, but statistically insignificant, negative relationship between PPD or CAL and GCF levels of IL-33. There was a weak, positive relationship between GCF and plasma concentrations of IL-33 in all 3 groups which did not reach statistical significance. The test showed a significant and very marked positive correlation between IL-33 and IL-1 $\alpha$ concentrations in GCF in the $\mathrm{H}$ group $(r=0.997, p=0.000), C P$ group $(r=0.999, p=0.000)$ and GAP group $(\mathrm{r}=0.884, \mathrm{p}=0.000)$ There was a statistically insignificant, moderately positive relationship among IL-33 concentrations in plasma with that of both IL-33 and IL- $1 \alpha$ concentrations in GCF of all 3 groups (Table 3 ).

\section{Discussion}

The present cross-sectional study was undertaken to compare and evaluate GCF and plasma levels of IL-33 and IL-1 $\alpha$ among periodontally healthy individuals, those with chronic, and those with aggressive periodontitis. Numerous studies have investigated the relationship between IL-33 and periodontal disease. While most in vitro studies have found that IL-33 was a central mediator of periodontal disease, the results of human studies have been inconclusive at best ${ }^{23)}$.

As chronic inflammatory diseases such as rheumatoid arthritis have been reported to affect levels of IL-33 ${ }^{17)}$, they were included as an exclusion criterion in the present study. To the best of our knowledge, this is the first study to report data on GCF and plasma concentrations of IL-33 and IL- $1 \alpha$ in periodontal disease.

Chronic periodontitis, which is prevalent mainly in adults, is a major cause of tooth loss, whereas aggressive periodontitis, which is characterized by severe and rapid progression, is found more in younger individuals. These two types of disease differ in many aspects, including age of onset, disease progression rate, major pathogenic mechanisms, familial aggregation, genetic susceptibility, and local factors. At present, clinical periodontal and radiographic findings along with patient history are commonly used in arriving at a diagnosis. At times, these periodontal parameters are insufficient to allow the establishment of an accurate diagnosis, however. Therefore, continued research is crucial in understanding the specific role of microbial factors as well as host factors if these two clinical phenotypes are to be better distinguished. One study has suggested an association between differences in the bacterial load in different types of periodontal disease and specific cytokine profiles ${ }^{2}$. This is supported by the results of the current study, which revealed a statistically significant difference in GCF and plasma levels of IL-33 between CP and GAP. Probing pocket depth and the CAL neither indicate current disease activity nor predict future progression. It is a major challenge in clinical periodontics to find a reliable, highly specific, and sensitive molecular marker of periodontal tissue destruction ${ }^{4)}$. 
Table 3 Correlations between gingival crevicular fluid IL-33, plasma IL-33, and GCF IL- $1 \alpha$ concentrations and clinical periodontal parameters.

\begin{tabular}{lccc}
\hline \hline \multicolumn{1}{c}{ STUDY GROUPS } & $\begin{array}{c}\text { GROUP H } \\
(\mathrm{r} \text { value })\end{array}$ & $\begin{array}{c}\text { GROUP CP } \\
(\mathrm{r} \text { value })\end{array}$ & $\begin{array}{c}\text { GROUP GAP } \\
(\mathrm{r} \text { value })\end{array}$ \\
\hline GCF IL-33 \& GCF IL-1 $\alpha$ & $0.997^{*}$ & $0.999^{*}$ & $0.884^{*}$ \\
GCF IL-33 \& GI & - & 0.050 & -0.075 \\
GCF IL-33 \& PPD & -0.258 & -0.365 & -0.114 \\
GCF IL-33 \& CAL & - & -0.307 & -0.254 \\
GCF IL-1 $\alpha$ \& GI & - & 0.061 & 0.066 \\
GCF IL-1 $\alpha$ \& PPD & -0.233 & -0.364 & -0.146 \\
GCF IL-1 $\alpha$ \& CAL & - & -0.301 & -0.149 \\
Plasma IL-33 \& GI & - & 0.406 & -0.468 \\
Plasma IL-33 \& PPD & 0.161 & -0.218 & -0.195 \\
Plasma IL-33 \& CAL & - & -0.171 & -0.218 \\
GCF IL-33 \& Plasma IL-33 & 0.338 & 0.184 & 0.228 \\
GCF IL-1 $\alpha$ \& Plasma IL-33 & 0.343 & 0.188 & 0.346 \\
\hline
\end{tabular}

Correlations between different parameters were analyzed by Spearman correlation test.

* statistically significant at $\mathrm{p}=0.000$;

— not applicable

Therefore, one of the goals of the present study was to determine possible correlations between clinical diagnostic parameters and IL-33 levels to evaluate their usefulness as a biomarker in identifying periodontal disease and monitoring treatment.

Expression of IL-33 increases in response to proteases, pathogen-associated molecular patterns, and proinflammatory stimuli. Tada et al. detected IL-33 in inflamed gingival epithelium of chronic periodontitis patients. They found that Porphyromonas gingivalis increased IL-33 expression in human gingival epithelial cells in vitro, and that protease-activated receptor-2 (PAR-2), as well as inhibitors of phospholipase C, p38, and NF- $\kappa \beta$, inhibited expression of IL-33 induced by $P$. gingiva${ }{ }^{30}{ }^{30)}$. In an in vitro study, it was reported that stimulation of human monocytes with Escherichia coli and $P$. gingivalis lipopolysaccharide upregulated IL-33 at both the mRNA and protein levels ${ }^{19)}$. Beklen et al. reported that IL-33 levels significantly increased in TNF- $\alpha$ stimulated human gingival fibroblasts as compared to in unstimulated fibroblasts ${ }^{3)}$. In a ligature-induced periodontitis model,
Köseoğlu et al. noticed that the experimental periodontitis group exhibited increased expression of IL-33 and RANKL compared with the healthy group. They concluded that IL-33 could be associated with the pathogenesis of periodontal disease ${ }^{11)}$. In a murine model of periodontal disease, Malcolm et al. demonstrated that expression of IL-33 and its receptor ST2 was elevated in gingival tissues of CP patients, and concluded that IL-33 plays a role in exacerbating bone loss in a RANKLdependent manner in the context of bacterial infection, suggesting that this pathway may be amenable to manipulation as a novel therapeutic target in periodontitis ${ }^{15)}$. The findings of the present study showed a gradual increase in IL-33 levels in GCF and plasma, from healthy patients to $\mathrm{CP}$, and from CP to GAP. This suggests that IL-33 may indeed play a role in the pathogenic pathways of periodontal disease. Further studies are required to quantify virulence factors such as gingipains and leukotoxin $\mathrm{A}$ in periodontitis patients, along with GCF and gingival tissue expression of IL-33 to establish if there is actually a concentration-dependent relationship among 
them.

In the present study, IL-33 was detected in all of the GCF and plasma samples. This was in contrast with in a previous study by Papathanasiou et al., who found that IL-33 was below detection level in all the GCF samples collected. They attributed many reasons to this finding, which included greater dilution of GCF during the assay; the inability of IL-33 to cross the junctional epithelium into the gingival crevice; degradation of IL-33 by proteases before reaching the GCF; and levels of IL-33 being much lower than the detection levels of the assay used ${ }^{22)}$.

Buduneli et al. found that differences among GCF, saliva, and plasma levels of IL-33 were insufficient to allow differentiation of chronic periodontitis from healthy periodontium. Their results were attributed to low sensitivity of the ELISA kits, a significantly lower volume of GCF in periodontally healthy patients, and ethnic differences between study populations. They suggest that analyzing other members of the IL-1 family along with IL-33 may provide a better understanding of their possible role in periodontal dis-

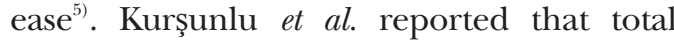
amounts of IL-33 were similar among GAgP, $\mathrm{CP}$, gingivitis, and periodontally healthy individuals. They concluded that IL-33 does not contribute to the pathogenesis of periodontal disease $^{12)}$.

In the present study, levels of IL- $1 \alpha$ showed an increase in GCF obtained from patients with periodontitis as compared to that obtained from healthy controls, a finding similar to that obtained in previous studies ${ }^{16)}$. The results of previous studies on GCF levels of IL-33 in periodontitis have been inconclusive, however. Therefore, the present study compared them with GCF concentrations of an already established alarmin, namely, IL- $1 \alpha$. Interleukin- $1 \alpha$ alerts the cells of the innate immune system to tissue damage during trauma or infection, as it can be released in the extracellular space after endothelial cell damage or mechanical injury ${ }^{18}$. The present study also included an additional study group of patients with GAP.
Gümü et al. reported statistically significant higher saliva IL-33 levels in CP patients than in aggressive periodontitis patients or those who were periodontitis-free, suggesting a relationship between periodontopathogens and salivary cytokine levels ${ }^{9}$. Sağlam et al. compared GCF levels of IL-33, saliva, and plasma obtained from periodontitis patients. They found that IL-33 concentrations were lower in the CP group than in the healthy or gingivitis groups, whereas salivary and plasma levels were similar ${ }^{25)}$. In another study, it was reported that salivary IL-33 concentrations were significantly higher in patients with obstructive sleep apnea syndrome than in the healthy control group, but no relationship was noted with periodontal parameters ${ }^{20)}$. The present study showed that IL-33 concentrations were greater in GCF or plasma obtained from patients with chronic or aggressive periodontitis than from healthy controls. Whole saliva represents a pooled sample, with contributions from all periodontal sites, whereas GCF is site-specific. Proteases are known to be elevated in the saliva of periodontitis patient ${ }^{33)}$ and may further reduce the levels of protein biomarkers in GCF. In the present study, GCF and plasma samples were selected for assessment taking into consideration the results of the previous studies. Concentrations of IL-33 and IL- $1 \alpha$ in GCF showed no correlation with the clinical parameters of inflammation. This finding may be explained by the episodic nature of periodontitis. This disease may have been in different phases (active or quiescent) in the patients in the periodontitis groups. Also, the present study recorded mainly soft tissue parameters, which might not be true indicators of underlying active bone resorption. Further studies are needed both before and after intervention (such as Phase I therapy) to determine whether there is a correlation between IL-33 levels and clinical indicators of disease such as PPD or CAL. Moreover, further study is also needed to establish whether IL-33 levels are associated with alveolar bone loss.

The negative, although statistically insignificant, correlation between PPD or CAL 
and IL-33 concentrations seen here may be attributable to the fact that in the initial stages of inflammation IL-33 participates in the anti-inflammatory response by an augmentation of the Th2 response. In the absence of treatment, however, extremely high levels of IL-33 and other pro-inflammatory cytokines are released, and these have been shown to activate mast cells and favour osteoclastogenesis ${ }^{8,21,31,32)}$.

In the present study, plasma levels of IL- $1 \alpha$ were below detection levels. Previous studies have detected IL-1 $\alpha$ in plasma from healthy and chronic periodontitis patients ${ }^{10)}$. This discrepancy between the current and earlier results may be partly attributable to the different assay kits used, as sensitivities will vary. To our knowledge, no previous studies have analyzed IL- $1 \alpha$ in plasma obtained from patients with aggressive periodontitis.

\section{Conclusion}

Interleukin-33 was detected in GCF and plasma obtained from healthy, chronic, and aggressive periodontitis patients. The levels of IL-33 were highest in GCF and plasma obtained from patients with aggressive periodontitis and lowest in those with healthy periodontium, with those observed in patients with chronic periodontitis in between. Interleukin- $1 \alpha$ was detected in GCF obtained from healthy, chronic, and aggressive periodontitis patients, but not in plasma. Concentrations of IL- $1 \alpha$ in GCF showed a significant correlation with those of IL-33. This suggests that IL-33 offers a useful biomarker of periodontal disease, as it can differentiate between healthy and diseased periodontal sites, similarly to the previously established alarmin IL-1 $\alpha$. Future studies with larger sample sizes, quantification of virulence factors, and intervention clinical trials will enhance the knowledge of the role of IL-33 in periodontal health and disease. Understanding the association between IL-33 levels and severity of chronic or aggressive periodontitis might open a new pathway for periodontal therapy in the future.

\section{Acknowledgements}

The authors acknowledge S.P. Jagannatha, honorary statistician, Bangalore, India, for helping prepare the statistics of the study; $\mathrm{R}$. Venkatswamy, technician, Department of Microbiology, Kempegowda Institute of Medical Sciences, Bangalore, India, for helping run the ELISA; and Dr. Premchandra Sagar, vice-chairman, for his support during the research period. The research for this study was self-funded. The authors report no conflict of interest pertaining to this study.

\section{References}

1) Allakhverdi Z, Smith DE, Comeau MR, Delespesse G (2007) Cutting edge: The ST2 ligand IL-33 potently activates and drives maturation of human mast cells. J Immunol 179(4):2051-2054.

2) Andrukhov O, Ulm C, Reischl H, Nguyen PQ, Matejka M, Rausch-Fan X (2011) Serum cytokine levels in periodontitis patients in relation to the bacterial load. J Periodontol 82(6): 885-892.

3) Beklen A, Tsaous Memet G (2014) Interleukin-1 superfamily member, interleukin-33, in periodontal diseases. Biotech Histochem 89(3): 209-214.

4) Buduneli N, Kinane DF (2011) Host-derived diagnostic markers related to soft tissue destruction and bone degradation in periodontitis. J Clin Periodontol 38:85-105.

5) Buduneli N, Özçaka Ö, Nalbantsoy A (2012) Interleukin-33 levels in gingival crevicular fluid, saliva, or plasma do not differentiate chronic periodontitis.JPeriodontol83(3):362368.

6) Burger D, Dayer JM, Palmer G, Gabay C (2006) Is IL-1 a good therapeutic target in the treatment of arthritis? Best Pract \& Res Clin Rheumatol 20(5):879-896.

7) Carriere V, Roussel L, Ortega N, Lacorre DA, Americh L, Aguilar L, Bouche L, Girard JP (2007) IL-33, the IL-1-like cytokine ligand for ST2 receptor, is a chromatin-associated nuclear factor in vivo. Proc Natl Acad Sci 104(1):282-287.

8) Cordero da Luz FA, Lima Oliveira AP, Borges D, Cristina Brígido P, Barbosa Silva MJ (2014) The physiopathological role of IL-33: new highlights in bone biology and a proposed 
role in periodontal disease. Mediators of Inflamm 2014:342410.

9) Gümü P, Nizam N, Nalbantsoy A, Özçaka Ö, Buduneli N (2017) Saliva, serum levels of interleukin-21,-33 and prostaglandin E2 in patients with generalised aggressive or chronic periodontitis. Oral Health \& Prev Dent 15(4): 385-390.

10) Hao L, Li JL, Yue Y, Tian Y, Wang M, Loo WT, Cheung MN, Chow LW, Liu Q, Yip AY, Ng EL (2013) Application of interleukin-1 genes and proteins to monitor the status of chronic periodontitis. Int J Biol Markers 28(1):92-99.

11) Köseoğlu S, Hatipoğlu M, Sağlam M, Enhoș Ș, Esen HH (2015) Interleukin-33 could play an important role in the pathogenesis of periodontitis. J Periodont Res 50(4):525-534.

12) Kurșunlu SF, Öztürk VÖ, Han B, Atmaca H, Emingil G (2015) Gingival crevicular fluid interleukin-36 $\beta$ (-1F8), interleukin-36 $\gamma$ (-1F9) and interleukin-33 (-1F11) levels in different periodontal disease. Arch Oral Biol 60(1):7783.

13) Lang N, Bartold PM, Cullinan M, Jeffcoat M, Mombelli A, Murakami S, Page R, Papapanou P, Tonetti M, Van Dyke T (1999) Consensus report: aggressive periodontitis. Ann Periodontol 4(1):53.

14) Löe H, Silness J (1963) Periodontal disease in pregnancy I. Prevalence and severity. Acta Odontologica Scandinavica 21(6):533-551.

15) Malcolm J, Awang RA, Oliver-Bell J, Butcher JP, Campbell L, Adrados Planell A, Lappin DF, Fukada SY, Nile CJ, Liew FY, Culshaw S (2015) IL-33 exacerbates periodontal disease through induction of RANKL. J Dent Res 94(7):968975.

16) Mathur A, Michalowicz B, Castillo M, Aeppll D (1996) Interleukin-1 alpha, interleukin-8 and interferon-alpha levels in gingival crevicular fluid. J Periodont Res 31(7):489-495.

17) Matsuyama $Y$, Okazaki H, Tamemoto $H$, Kimura H, Kamata Y, Nagatani K, Nagashima T, Hayakawa M, Iwamoto M, Yoshio T, Tominaga SI (2010) Increased levels of interleukin 33 in sera and synovial fluid from patients with active rheumatoid arthritis. J Rheumatol 37(1):18-25.

18) Moussion C, Ortega N, Girard JP (2008) The IL-1-like cytokine IL-33 is constitutively expressed in the nucleus of endothelial cells and epithelial cells in vivo: a novel 'alarmin'? PloS One 3(10):e3331.

19) Nile CJ, Barksby E, Jitprasertwong P, Preshaw PM, Taylor IJ (2010) Expression and regulation of interleukin-33 in human monocytes. Immunology 130(2):172-180.

20) Nizam N, Basoglu OK, Tasbakan MS,
Nalbantsoy A, Buduneli N (2014) Salivary cytokines and the association between obstructive sleep apnea syndrome and periodontal disease. J Periodontol 85(7):e251-e258.

21) Palmer G, Talabot-Ayer D, Lamacchia C, Toy D, Seemayer CA, Viatte S, Finckh A, Smith DE, Gabay C (2009) Inhibition of interleukin-33 signaling attenuates the severity of experimental arthritis. Arthritis Rheum: Official Journal of the American College of Rheumatology 60(3):738-749.

22) Papathanasiou E, Teles F, Griffin T, Arguello E, Finkelman M, Hanley J, Theoharides TC (2014) Gingival crevicular fluid levels of interferon- $\gamma$, but not interleukin- 4 or -33 or thymic stromal lymphopoietin, are increased in inflamed sites in patients with periodontal disease. J Periodont Res 49(1):55-61.

23) Rodrigues WF, Miguel CB, Mendes NS, Oliveira CJF, Ueira-Vieira C (2017) Association between pro-inflammatory cytokine interleukin-33 and periodontal disease in the elderly: a retrospective study. J Indian Soc Periodontol 21(1):4-9.

24) Roussel L, Erard M, Cayrol C, Girard JP (2008) Molecular mimicry between IL-33 and KSHV for attachment to chromatin through the H2A-H2B acidic pocket. EMBO Reports 9(10):1006-1012.

25) Sağlam M, Köseoğlu S, Aral CA, Savran L, Pekbağrıyanık T, Çetinkaya A (2017) Increased levels of interleukin-33 in gingival crevicular fluids of patients with chronic periodontitis. Odontology 105(2):184-190.

26) Salvi GE, Lang NP (2005) Host response modulation in the management of periodontal diseases. J Clin Periodontol 32:108-129.

27) Schmitz J, Owyang A, Oldham E, Song Y, Murphy E, McClanahan TK, Zurawski G, Moshrefi M, Qin J, Li X, Gorman DM (2005) IL-33, an interleukin-1-like cytokine that signals via the IL-1 receptor-related protein ST2 and induces $\mathrm{T}$ helper type 2-associated cytokines. Immunity 23(5):479-490.

28) Seymour GJ (1987) Invited review: Possible mechanisms involved in the immunoregulation of chronic inflammatory periodontal disease. J Dent Res 66(1):2-9.

29) Seymour GJ (1991) Importance of the host response in the periodontium. J Clin Periodontol 18(6):421-426.

30) Tada H, Matsuyama T, Nishioka T, Hagiwara M, Kiyoura Y, Shimauchi H, Matsushita K (2016) Porphyromonas gingivalis gingipaindependently enhances IL-33 production in human gingival epithelial cells. PLoS One 11(4):e0152794.

31) Xiangyang Z, Lutian Y, Lin Z, Liping X, Hui S, 
Jing L (2012) Increased levels of interleukin-33 associated with bone erosion and interstitial lung diseases in patients with rheumatoid arthritis. Cytokine 58(1):6-9.

32) Xu D, Jiang HR, Kewin P, Li Y, Mu R, Fraser AR, Pitman N, Kurowska-Stolarska M, McKenzie AN, McInnes, IB, Liew FY (2008) IL-33 exacerbates antigen-induced arthritis by activating mast cells. Proc Natl Acad Sci 105(31):10913-10918.

33) Zhang L, Henson BS, Camargo PM, Wong DT (2009) The clinical value of salivary biomarkers for periodontal disease. Periodontol 2000: 51(1):25-37.
Correspondence:

Dr. Sujatha Pai B

\#811, 10th main road,

Jayanagar 4th block,

Bangalore-560011, Karnataka, India

Ph: +91-9008490033

Landline: 080-22449350

E-mail: paisuj@gmail.com 